\title{
Hacia prácticas integrales en arquitectura, un recorrido histórico para reflexionar sobre los desafíos pendientes
}

Towards integral practices in architecture, a historical journey to reflect on the pending challenges

\section{María Eugenia Durante}

https://orcid.org/0000-0001-5827-8812

durantemariaeugenia@gmail.com

Centro Interdisciplinario de Estudios Complejos | Facultad de Arquitectura

y Urbanismo | Universidad Nacional de La Plata | Argentina

\section{RESUMEN}

La integralidad como enfoque permite volver sobre la relación de la formación universitaria y las problemáticas sociales, a partir de reflexionar sobre los sentidos de la construcción y trasmisión del conocimiento en los diversos ámbitos de la Universidad, en este caso, de las facultades de arquitectura. Las problemáticas habitacionales y urbanas interpelan a la formación de los y las arquitectas desde sus inicios, principalmente como bandera del sector estudiantil lo que obliga a repensar la propuesta formativa y sus vínculos con la sociedad. Este artículo propone realizar un recorrido histórico, primero, sobre los enfoques generales desde los que se pensó la relación de la Universidad y las problemáticas sociales, para luego indagar en las formas particulares que esta relación adoptó en la facultad de arquitectura de la UBA desde su creación hasta mediados de los años setenta. Volver sobre la historia reciente local permite rastrear diversas experiencias prácticas que pensaron el problema social desde la formación, preguntándonos cómo se articularon los diversos ámbitos (docencia, investigación y extensión), así como divisar cuáles fueron los actores, procesos e intereses que permitieron los cambios, para arribar a reflexiones que ayuden a pensar un desafío vigente.

\section{PALABRAS CLAVE}

formación de arquitectura, historia reciente, hábitat popular, Universidad-Sociedad 


\section{KEY WORDS}

architecture schools, recent history,

popular habitat, University-Society

\section{ABSTRACT}

Integrality as an approach allows us to return to the relationship between university education and social problems, starting from reflecting on the meanings of the construction and transmission of knowledge in the various areas of the University, in this case, the architecture schools. Housing and urban problems have challenged the formation of architects from the beginning, mainly as a flag for the student sector, which forces us to rethink the training proposal and its links with society. This article proposes to carry out a historical journey, first, on the general approaches from which the relationship of the University and social problems was thought, to then investigate the particular forms that this relationship adopted in the UBA's faculty of architecture from its creation until the mid-seventies. Going back over recent local history allows us to trace various practical experiences that thought about the social problem from training, asking ourselves how the various areas were articulated (teaching, research and extension), as well as identifying which were the actors, processes and interests that allowed the changes, to arrive at reflections that help to think about a current challenge. 
En un contexto donde las problemáticas socio-territoriales vuelven a interpelar a los y las profesionales que forman las facultades de arquitectura, este trabajo se propone volver, desde la perspectiva de la integralidad, sobre algunos episodios de la historia local donde se apuntó a repensar el diálogo entre la Universidad y la Sociedad. Dicha perspectiva se retoma de los trabajos que se realizan desde la Universidad de la República, en Uruguay, donde la integralidad es entendida "como la articulación de las funciones universitarias (enseñanza, extensión e investigación), interdisciplina y diálogo de saberes (científicos y populares)" (Stevenazzi y Tommasino, 2017: 55), obliga a pensar los "entre", la relación entre diversos ámbitos, actores, perspectivas de la universidad, para entretejer nuevos rumbos para otros mundos posibles y necesarios. Una perspectiva que propone repensar la relación con "el afuera", esa realidad a la que la universidad debe su existencia, y de la que parece aislarse; repensar estos vínculos disolviendo fronteras, y entendiendo a la universidad como parte del proceso social y político. Deudores de la corriente crítica de extensión, las prácticas integrales promueven la incorporación de la extensión a la práctica educativa cotidiana, que se constituye en la introducción de un vector político, de un factor de ruptura con las tradiciones dominantes, que interpela las estructuras, métodos y contenidos de la Universidad.

\section{las prácticas integrales promueven la incorporación de la extensión a la práctica educativa cotidiana, que se consti- tuye en la introducción de un vector político, de un factor de ruptura con las tradiciones dominantes, que interpela las estructuras, métodos y contenidos de la Universidad.}

Con este enfoque como horizonte de sentido, el artículo se introduce recorriendo de manera breve los paradigmas que marcaron el debate entorno a la relación Universidad-Sociedad, para luego recorrer diversos episodios de la historia reciente de la Facultad de Arquitectura, Diseño y Urbanismo (en adelante FADU) de la Universidad de Buenos Aires (UBA) donde se configuraron diversas formas para repensar 
dicha relación. El objetivo principal es problematizar la propuesta de la integralidad a partir de recorrer diversos episodios históricos que permitan entender la complejidad de los procesos, actores y prácticas desde las que hacer posible su configuración como un horizonte de sentido posible en la formación de arquitectura.

\section{La relación Universidad-Sociedad}

Cuando se habla de la relación entre los problemas de la realidad social y la Universidad se suele apuntar al ámbito de la extensión, entendido como aquel configurado históricamente para su vinculación social. Con orígenes en Gran Bretaña a fines del siglo XIX, la extensión universitaria se desarrollará con fuerza en Latinoamérica a partir de la Reforma Universitaria de Córdoba de 1918, donde se "conformó las bases de un nuevo contrato social entre la sociedad y las universidades públicas a través de la extensión" (Rama, 2009: 264). Una extensión que, en sus inicios, tuvo un fuerte perfil culturalista, desde donde se transmitían los valores y saberes que constituían una "devolución" a la sociedad, de parte de un sector que buscaba "legitimar sus demandas de autonomía y recursos financieros, al interior de los sectores excluidos directamente de sus beneficios, así como integrar en redes culturales y aglutinar más sólidamente a los actores cercanos a la periferia universitaria" (Rama, 2009: 264). La Reforma parecía augurar la función social de la universidad latinoamericana cuyos enunciados, en muchas casos, serían "más una declaración de aspiraciones o una enunciación del deber ser de la universidad reformada, que una descripción de su realidad" (Tunnerman, 2003: 82).

\section{Una extensión que, en sus inicios, tuvo un fuerte perfil cultu- ralista, desde donde se transmitían los valores y saberes que constituían una "devolución" a la sociedad, de parte de un sector que buscaba "legitimar sus demandas de autonomía y recursos financieros, al interior de los sectores excluidos directamente de sus beneficios, así como integrar en redes culturales y aglutinar más sólidamente a los actores cercanos a la periferia universitaria"}

El tránsito hacia la modernidad de la universidad en Latinoamérica, estuvo signado por un crecimiento significativo de su matrícula, la aparición de la universidad privada y la diversificación de las propuestas de la educación superior. A medida que aumentó la matrícula en las universidades, la participación estudiantil en la extensión cultural también se incrementó. Hacia mediados de siglo XX, con la radicalización políti- 
ca del movimiento estudiantil, y el aumento de la conflictividad debido al desfinanciamiento de las universidades, parte de la comunidad universitaria se embanderó detrás de las consignas de un cambio social y político, "lo cual promovió y proyectó nuevos paradigmas sobre la extensión, asociadas al creciente nuevo rol político de las Universidades en las sociedades de los 60 y 70" (Rama, 2009: 270). En este contexto, el modelo de extensión con énfasis cultural cambia por uno de perspectiva crítica y de transformación social, cambios que se apoyan en la idea de "reconocer que la educación es un subsistema social que forma parte del sistema social global y, por lo mismo, es un reflejo de éste, pero goza de suficiente autonomía como para, a su vez, influir sobre la sociedad y propiciar su cambio" (Tunnerman, 2003: 274). En la construcción del modelo de extensión con perspectiva crítica influyeron las ideas de Paulo Freire, Augusto Salazar Bondy, Orlando Fals Borda, entre muchos otros/as, al igual que el avance de las corrientes progresistas $y$ de izquierda en todo el continente, que encuentran en el triunfo de la revolución cubana (1959) un catalizador importante.

\section{el modelo de extensión con énfasis cultural cambia por uno de perspectiva crítica y de transformación social, cambios que se apoyan en la idea de "reconocer que la educación es un subsistema social que forma parte del sistema social glo- bal y, por lo mismo, es un reflejo de éste, pero goza de sufi- ciente autonomía como para, a su vez, influir sobre la socie- dad y propiciar su cambio"}

La perspectiva cultural y la crítica, según Cano (2017), se desprenden de la tradición reformista, la cual se vincula a la genealogía europea de la extensión universitaria. Además de la reformista, el autor reconoce a la tradición positivista, de cuño norteamericano, las cuales se han solapado y articulado en diferentes coyunturas históricas. Esta segunda tradición se basa en el "modelo de transferencia tecnológica" que forma parte del circuito "ciencia-innovación- aplicación". A partir de la posguerra, este modelo ganará terreno en Latinoamérica, lo que generará un desplazamiento de la tradición reformista e ideas de la universidad, hacia una "que concibe a la universidad como un modelo corporativo inserto en un mercado competitivo para producir y vender bienes o servicios, y que participa en el desarrollo económico a través del entrenamiento de fuerza de trabajo y de investigación productiva" (Casanova, 2004:206). En este modelo la extensión universitaria profundiza la relación con la empresa privada, busca otras fuentes de financiamiento externo, y se consolida a través de la lógica mercantil (Cano, 2017:17).

La extensión no será el único ámbito donde se dirima la relación 
universidad-sociedad, sin embargo, gran parte de las discusiones que se comentaban configuran la matriz general con la que la universidad piensa en los problemas de la realidad social, resultando la extensión una salida práctica donde visualizarlas. La investigación y la docencia también problematizan sobre estas urgencias, revisando tanto sus métodos como sus contenidos. En el recorrido por algunos episodios que se dan en la FADU durante el siglo XX se puede visualizar la diversidad de formas.

\section{Prácticas de legitimación social}

En la UBA se crea la primera carrera de arquitectura del país, su primer graduado es de 1878, se convirtió en Escuela en 1901 y en facultad en 1948. Desde su fundación hasta los años cincuenta, va a prevalecer una enseñanza basada en el modelo de las Bellas Artes, donde se gestan los primeros "arquitectos-artistas" del país. A medida que se va ampliando la matrícula y números de graduados/as, los mismos apuntan a consolidar su campo profesional construyendo sus instituciones profesionales y marcos normativos que legitimen las prácticas, proceso que el trabajo de Cirvini (2003) desarrolla en profundidad. En el seno de la FADU, la continuidad del perfil tradicional y conservador será resistido por los y las estudiantes, quienes desde los años veinte comienzan a reclamar la modernización de los métodos y saberes impartidos. Al calor del movimiento reformista, luchaban por la renovación de la Escuela y de los saberes disciplinares, desde lugares como el Centro de Estudiantes de Arquitectura (CEA). Para los estudiantes el sistema de Bellas Artes "ya no les resultaba válido para afrontar las soluciones que la arquitectura debía proveer en la sociedad contemporánea" (Schmit, Silvestri y Rojas, 2004:36).

El CEA, fundado en 1908, rápidamente se constituyó en un núcleo de sociabilidad importante, y desde allí se activaron las primeras acciones de difusión y propaganda como la Revista de Arquitectura, creada en 1915. A este órgano de difusión se suma la Sociedad Central de Arquitectos en 1917, lo cual muestra el fuerte vínculo que inicialmente tenía dicha institución profesional (fundada en 1886) con el ámbito de la formación universitaria. El desarrollo de carreras como arquitectura a principios de siglo se vincula a la constitución del Estado moderno en el país que estableció la oferta y demanda de los profesionales y sus incumbencias. Esta demanda es acompañada por el desarrollo de la técnica y la Universidad, así como diversas estrategias que permitieron la constitución disciplinar y profesional, donde se definió un campo de conocimientos como propios, a la vez que se determinaron las prácticas profesionales específicas y mecanismos de legitimación particulares.

Durante el primer peronismo suceden años conflictivos y contradictorios, en la FADU, amplios sectores cuestionan las políticas del go- 
bierno, sin embargo, también serán años de reformas en las escuelas (algunas pasarán a ser facultades) y de instauración de la gratuidad que masificó las universidades. Estas renovaciones no van de la mano de cambios en sus planteles docentes, cosa que sucede recién hacia los años cincuenta, con la visita de profesores extranjeros, la consolidación de una generación joven de graduados/as, y la multiplicación de grupos de estudio y cursos paralelos por fuera de la currícula (Cravino, 2015). Varias de las discusiones hacían eje en la autonomía universitaria y su vinculación con la política gubernamental, lo cual refleja una de las preocupaciones centrales de la comunidad universitaria formada al calor de la reforma del '18. Una autonomía que permitió configurar la demarcación del campo específico de la disciplina y profesión, que legitime y jerarquice socialmente sus prácticas y discursos, para garantizar su demanda en el mercado laboral.

\section{Prácticas para la incorporación del problema social}

En el período que va del golpe a Perón en 1955 a 1966, se desarrolla un clima complejo en la Universidad, con el peronismo proscripto y las diferencias que surgieron a lo interno de las fuerzas que impulsaron la Revolución Libertadora. En 1955, los y las estudiantes toman la FADU y reclaman por la renovación de los planes de estudio, profesores y autoridades. En este contexto, "Se produce una renovación tanto en lo conceptual como en lo metodológico. Se pasa de una enseñanza de fuerte impronta Beaux Arts a una facultad moderna" (Batlle, 2018:4). La renovación incluiría en los contenidos el abordaje de programas de vivienda social y equipamiento urbano para sectores populares, en el desarrollo de proyectos dentro de los talleres y en las primeras acciones de extensión e investigación. Una demanda de abordaje de la cuestión social que se vinculaba estrechamente a las necesidades de expertos/as del Estado para atender a las problemáticas urbanas y habitacionales de los sectores populares que crecían en villas y asentamientos.

Diversas prácticas pioneras en el abordaje del problema del hábitat popular se dieron en el marco de las acciones en Isla Maciel que impulsaba el Departamento de Extensión Universitaria (DEU) de la UBA, creado en 1956 (Brusilovsky, 1998). Las acciones apuntaban a dos aspectos: facilitar el acceso a la Universidad de sectores más amplios de la sociedad, y lograr una re-estructuración de la Universidad para que responda a las necesidades reales del país. Estas experiencias en Isla Maciel constituyeron uno de los primeros procesos que permitieron generar un trabajo territorial y vivencial concreto de los y las estudiantes con las problemáticas sociales. Como expresaba el propio DEU, se trataba de comprender que el aprendizaje no estaba solo en los libros y profesores, sino también charlando con las personas y conociendo sus realidades. 


\section{comprender que el aprendizaje no estaba solo en los libros y profesores, sino también charlando con las personas y cono- ciendo sus realidades}

En este marco, se lleva adelante una serie de proyectos desde la FADU que se articulan con los esfuerzos del DEU. En 1960 se le pide al taller de Wladimiro Acosta el proyecto de un conjunto de viviendas para los integrantes de la Cooperativa de Vivienda constituida entre los habitantes de la villa miseria de Maciel (Gaite, 2007). El proyecto fue desarrollado junto a un equipo de estudiantes y nunca llegó a construirse. A este se suman en vínculo con el DEU, por un lado, el taller de los profesores Odilia Suárez y Francisco García Vázquez, y, por otro, el de Horacio Berretta. Trabajos que se apoyaban en el diálogo interdisciplinario, en instancias participativas con los y las pobladoras y el diálogo con diferentes facultades en un mismo territorio.

El área de investigación, por su parte, crece con fuerza en el modelo de Universidad desarrollista y la consolidación del sistema científico nacional. Uno de los primeros esfuerzos de investigación abocados al problema de la vivienda popular será el Instituto de la Vivienda en la UBA, el cual se crea a inicios de los años sesenta. Estos primeros desarrollos de la investigación abocados a los problemas de la vivienda popular, permiten una profundización de los discursos especializados, desde el enfoque cientificista, donde la ciencia jerarquiza los conocimientos, por sobre los planteos "politizados". La investigación permitió experimentar, analizar, sistematizar y teorizar sobre las nuevas prácticas y saberes.

\section{Prácticas para la incorporación del problema político-institucional}

En julio de 1966 la Universidad es interrumpida por el gobierno de facto de Onganía, quien suprime por ley la autonomía universitaria y reprime a las expresiones estudiantiles en lo que se denominó la "Noche de los bastones largos". Se desmanteló el proceso que se venía construyendo, y en la UBA se da una renuncia masiva de profesores en todas las facultades. El objetivo de la intervención del gobierno de Onganía de "despolitizar" la universidad, tendría como resultado una mayor participación política de los y las estudiantes, volcados a las agrupaciones de izquierda y del peronismo, que resurgió con fuerza. En el proceso de radicalización política de los estudiantes y profesionales universitarios, la politización opera en la impronta social que le imprime el problema del hábitat popular a la profesión, radicaliza sus discursos y articula con fuerza hacia la práctica arquitectónica con la práctica militante. En este contexto, se profundiza la crítica a las instituciones, tanto a las Universidades, vistas como reproductoras de 
las lógicas de un modelo económico contra el que se luchaba, y a las mismas formas de participación estudiantil, a las cuales se entendía viciadas y burocratizadas, por lo que se configuran espacios de poder como los cuerpos de delegados (Bonavena, 2005).

Hacia los años setenta, se gestan una serie de experiencias que buscaron repensar la formación y prácticas de la arquitectura junto a los movimientos sociales. Prácticas que trascienden la idea de abordaje del problema social, para incrustar el mismo dentro de la lucha política. Las diversas propuestas de reestructuración de las facultades de arquitectura, con sus particularidades, están pensando otra forma de vincular sus ámbitos interna y externamente, integrando las voces de los y las estudiantes así como de los y las pobladoras y sus luchas. La universidad pública parecía erigirse como el único ámbito propicio donde practicar nuevas formas de entrelazar lo profesional con la política. Como señala Silvestri, quien busca experiencias radicales "las encuentren en el breve período que va entre 1972 y 1974 en el área de la enseñanza de arquitectura, y no en las prácticas profesionales, inevitablemente atravesadas por los compromisos con el Capital o con el Estado" (2014: 82).

\section{La universidad pública parecía erigirse como el único ámbi- to propicio donde practicar nuevas formas de entrelazar lo profesional con la política}

Cuando asume Cámpora, en 1973, se produce la renovación de autoridades en la UBA y la FADU que auguran un breve proceso de cambios. La enseñanza se organizó en tres áreas principales: el Departamento de Ciencias Humanas, el Departamento de Técnicas Constructivas, y el Departamento de Diseño. Comenzaría allí a gestarse lo que se conoció como los Talleres Nacionales y Populares (TA.NA.PO.), impulsados por estudiantes y docentes de la Juventud Peronista, Montoneros y otras organizaciones. Se crea el Instituto de Investigaciones y Proyectos (IIP) cuyos propuestas buscan vincular la producción de contenidos con la formación y las formulación de políticas públicas. En estas experiencias, se configuran proyectos y programas que se realizaban en diálogo tanto con las instituciones estatales como con las organizaciones sociales y el movimiento villero. Los TANAPO no serán la única experiencia, como antecedente previo se encontraba el paradigmática Taller Total de Córdoba (Lamfri, 2007; Malecki, 2016) y propuestas similares que suceden en La Plata, Rosario y Tucumán, que han sido escasamente estudiados. Todas estas experiencias propusieron repensar las estructuras académicas y contenidos en la formación de arquitectos y urbanistas, así como las estructuras de poder y espacios de participación. Se integraban la formación, extensión e 
investigación, dentro de un proyecto de Universidad, que se pensaba en el marco de un horizonte político distinto. Estos procesos se ven interrumpidos con la intervención de las universidades de María Estela Martínez de Perón en 1974, y con la apertura de un proceso de represión y persecución política, el cual se profundiza con el gobierno militar que se instaura el 24 de marzo de 1976.

\section{Hacia prácticas integrales en arquitectura, reflexiones finales}

El breve recorrido por las formas que adoptó la vinculación con las problemáticas sociales de la FADU durante gran parte del siglo XX, permite divisar la complejidad del entramado de actores, procesos e intereses que se vinculan a la configuración de la formación disciplinar y profesional. Los ámbitos de formación, extensión e investigación inician un recorrido diferenciado y se vinculan y re-estructuran cuando los cambios en la Universidad son parte de cambios socio-políticos en contextos que la trascienden. Lejos de poder particularizar en las múltiples formas prácticas y entramados, el recorrido apuntaba a abrir, desde las experiencias históricas, nuevas preguntas desde dónde entrar al problema de la integralidad. ¿Qué actores y estrategias permiten pensar los cambios necesarios? ¿Cómo se vinculan estos ámbitos con el mundo laboral e instituciones profesionales? ¿Cómo integrar los ámbitos externos a la Universidad donde también se configura el saber disciplinar y profesional?

Por otro lado, volver sobre la historia, permite visualizar la importancia de entender la integralidad no como mero andamiaje formal, sino enfatizando en su potencia para abordar el vínculo con las problemáticas sociales, trascendiendo la idea de que sólo es tarea del ámbito de la extensión. Una perspectiva que vuelve sobre la capacidad de la extensión para reconfigurar, integrar y renovar todos los componentes del acto educativo. Permite repensar los roles de quienes saben y quienes aprenden, deconstruyendo las lógicas tradicionales, e incorporando a los actores sociales y la realidad con la que se interactúa como agentes educativos. Y coloca el eje sobre la trascendental pregunta de ¿qué es valioso enseñar? en un contexto actual, donde su emergencia es latente.

volver sobre la historia, permite visualizar la importancia de entender la integralidad no como mero andamiaje formal, sino enfatizando en su potencia para abordar el vínculo con las problemáticas sociales, trascendiendo la idea de que sólo es tarea del ámbito de la extensión. Una perspectiva que vuelve sobre la capacidad de la extensión para reconfigurar, integrar y renovar todos los componentes del acto educativo 


\section{BIBLIOGRAFIA}

Batlle, S. (2018). "Los sesenta. Enseñanza y profesión". En En Batlle, S. y Méndez Mosquera, S. (coord.), De Alumnos y Arquitectos. Buenos Aires: Archivo DAR, FADU-UBA.

Bonavena, P. (2005). “Cuerpos de delegados en la Facultad de Arquitectura de la UBA y de la Escuela de Bellas Artes Prilidiano Pueyrredón", Revista Praxis, (1).

Brusilovsky, S. (1998). "Recuperando una experiencia de democratización institucional y social: la extensión universitaria en la Universidad de Buenos Aires (1955-1966)". En Revista de Investigaciones del Instituto de Ciencias de la Educación, (12).

Cano, A. (2017). "La extensión universitaria y la universidad latinoamericana: hacia un nuevo 'orden de anticipación' a 100 años de la revuelta estudiantil de Córdoba"En +E, Revista de Extensión Universitaria, (7).

Casanova, H. (2004). "La Universidad hoy". En Casanova, H y Lozano, C. (eds.), Educación, universidad y sociedad: el vínculo crítico. Barcelona: Universitat de Barcelona.

Cirvini, A. (2003). Nosotros los Arquitectos. Campo disciplinar y profesión en la Argentina moderna. Buenos Aires: Fondo Nacional de las Artes.

Cravino, A. (2015). "Nosotros somos la Universidad". XI Jornadas de Sociología. Buenos Aires: Facultad de Ciencias Sociales.

Gaite, A. (2007). Wladimiro Acosta. Textos, proyectos, obras. Testimonios sobre el maestro. Buenos Aires: Nobuko.

Lamfri, N. (2007). Urdimbres. El Taller Total. Un estudio de caso. Tesis de Maestría en Investigación Educativa, Córdoba.

Malecki, S. (2016). “Crisis, radicalización y política en el Taller Total de Córdoba, 1970-1975". Prohistoria, (25), 79-103.

Rama, C. (2009). La universidad latinoamericana en la encrucijada de sus tendencias. Santo Domingo: Universidad del Caribe.

Schmidt, C.; Silvestri, G. y Rojas, M. (2004). "Enseñanza de arquitectura", en Liernur, J. F. y Aliata, F. (comp.) Diccionario de arquitectura en la Argentina, 32-44. Buenos Aires: Clarín Arquitectura.

Silvestri, G. (2014). "Alma de arquitecto. Conformación histórica del 'habitus' de los proyectistas del hábitat", Registros, 10 (11), 72-97.

Stevenazzi, F. y Tommasino, H. (2017). "Universidad e integralidad, algunas 
reflexiones sobre procesos de búsqueda y transformación". En Carlos A. de Santos... [et al.]. (2017) Fronteras universitarias en el Mercosur: debates sobre la evaluación en prácticas en extensión, 55-72. Córdoba: Universidad Nacional de Córdoba.

Tunnerman, C. (2003). La universidad latinoamericana ante los retos del siglo XXI. México: UDUAL. 